\title{
Study of Circular Reactive Powder Concrete-filled Steel Tube Stub Columns under Axial Compression
}

\author{
Hua Luo ${ }^{1}$, Weiwei Wang ${ }^{1, *}$, Guanghui Wang ${ }^{1}$ and Bo Pang ${ }^{2}$ \\ ${ }^{1}$ College of Civil Engineering and Architecture, Hunan Institute of Science and Technology, Yueyang 414000, China \\ ${ }^{2}$ Department of Civil and Environmental Engineering, University of California, Davis, CA 95616, United States
}

Received 29 August 2018; Accepted 1 November 2018

\begin{abstract}
As a fundamental mechanical problem in steel and concrete composite structures, the axial compressive behavior of reactive powder concrete (RPC)-filled steel tube stub columns has been a concern of scholars worldwide. At present, the analysis method of RPC-filled steel tube is based on nonlinear finite element method and equivalent uniaxial stress-strain analysis model, but the analysis process is complicated and cannot accurately describe the interaction between the steel tube and RPC. Thus, this study proposed a nonlinear analytical procedure to evaluate the mechanical properties of steel tube and RPC accurately at different compressing stages. The method was employed to predict the load-deformation curves of RPC-filled steel tube stub columns under axial compression. Compressing experiments were conducted on such columns, and the characteristic hoop coefficient was derived. Comparison analysis was performed to verify the accuracy and efficiency of the analytical procedure. Results demonstrate that the characteristic hoop coefficient is a critical value for assessing whether the steel tube yields when columns reach the ultimate bearing capacity. Columns with small hoop coefficient have good ductility, but the material utilization rate of the steel tube is not high. Columns with large hoop coefficient have weak ductility and residual deformation capacity. Moreover, columns with characteristic hoop coefficient can reach good ductility and high material utilization rate. The characteristic hoop coefficient determined by the test analysis in this study is approximately 1.3. The analytical results are generally in good agreement with the experimental results until the starting position of strain hardening or local plastic buckling. The proposed method provides a good prospect for optimizing the design of RPC-filled steel tube columns.
\end{abstract}

Keywords: Reactive Powder Concrete, Constraint, Equilibrium condition, Deformation coordination, Constitutive model

\section{Introduction}

Modern engineering structures continue to develop in the high-rise, large-span, heavy-duty and giant direction. However, conventional structural materials and component forms cannot fully meet the development needs.

A reactive powder concrete (RPC)-filled steel tube system is formed by filling a steel tube with ultra-highperformance RPC. The steel tubes surrounding the RPC columns eliminate permanent formwork, thereby reducing construction time. The steel tube acts as a longitudinal and transverse reinforcement and provides a confining pressure to the RPC, thereby introducing the RPC core to a triaxial stress state. The system has ultra-high carrying capacity and excellent deformation performance [1-3]; hence, it is widely used in high-rise buildings, bridge engineering, and underground engineering. As a fundamental mechanical problem in steel and concrete composite structures, the axial compressive behavior of RPC-filled steel tube stub columns is a concern of scholars worldwide.

A mutual force is generated in the interface under compression due to the difference of the lateral deformation performance of the steel tube and core RPC. The core RPC is passively subjected to lateral pressure and undergoes a stress process from uniaxial compression to triaxial

*E-mail address: 13873065820@163.com

ISSN: 1791-2377 @ 2018 Eastern Macedonia and Thrace Institute of Technology. All rights reserved. doi:10.25103/jestr.115.18 compression. In comparison with ordinary concrete, RPC improves internal porosity and weak interface structure, obtains high strength and durability by improving the fineness and activity of components, and minimizes the porosity and micro-cracks inside the material. Therefore, the mechanical properties of RPC are different from those of ordinary concrete. Furthermore, the design and analysis method of ordinary concrete-filled steel tubes are not applicable to RPC-filled steel tube structures.

Scholars worldwide have conducted considerable study on the performance of RPC-filled steel tube columns under a simple stress state, and some calculation methods suitable for engineering design are provided [4-6]. However, these studies mainly focus on estimating the failure mode of columns and the ultimate bearing capacity, including the equivalent uniaxial stress-strain analysis model, but they cannot accurately describe the interaction between the steel tube and RPC. Therefore, an analytical method that can accurately locate the different mechanical stages of RPCfilled steel tube must be established. Moreover, the influence of various parameters on the stress and strain of steel tube and RPC and their mutual restraint in the whole process of RPC-filled steel tube stub columns under axial compression must be analyzed.

On the basis the analysis, this study proposes a nonlinear analytical procedure to evaluate the mechanical properties of steel tube and RPC accurately at different compressing stages. This procedure is simpler than the 
nonlinear finite element method. This study aims to establish a foundation for the further analytical analysis of RPC-filled steel tube structures.

\section{State of the art}

Study on RPC-filled steel tube is still in the initial stage, given that it is a new type of steel-concrete composite structure. Thus far, scholars worldwide have performed numerous studies on the performance of RPC-filled steel tube structure through experimental and FEA methods. They have provided calculation methods that are suitable for engineering design. Hua et al. [7] conducted an experimental study on the influence of different loading methods to the behavior of RPC-filled steel tube columns subjected to axial load. The two different loading methods used in actual engineering projects, namely, full-section and core-concrete loading were considered. The failure mode and ultimate bearing capacity of the specimens were discussed, but the effects of various parameters on the stress and strain of the steel tube and RPC were not analyzed. Min et al. [8] proposed a unified formula to calculate the axial loadbearing capacity of CFST columns with either circular or polygonal sections. The interface bonding performance and size effect on the basis of unified strength and thick-walled cylinder theories were considered. Parametric studies were also conducted to investigate the influence of the unified strength theory parameter, confinement index, and RPC strength. Practical calculation formulas for axial compression bearing capacity were proposed on the basis of statistical analysis, but the influence of various parameters on the interaction between the steel pipe and RPC was not analyzed. Guo et al. [9-12] conducted an experimental study on four large-scale RPC-filled steel tube column specimens to investigate the blast-resistant capacities of such columns. After exposure to fire, the time history curves of the reflected overpressure of blast load and displacements and strains of specimens were obtained. Results showed that RPC-filled steel tubular columns maintain an excellent blast resistance after exposure to fire, and the core RPC column can be effectively constrained by steel tube under explosion load. RPC and steel tube are considered to analyze the failure mode and ultimate bearing capacity of the structure. The mechanical mechanism of the material is not discussed. The mechanical performance of the RPC material must be studied to determine the working mechanism of the RPCfilled steel tube structure and the interaction between the steel tube and RPC. Both materials are considered integral structures while analyzing the failure mode and ultimate bearing capacity of the structure in existing studies. The mechanical mechanism of the material is not discussed.

Scholars have proposed corresponding concrete-filled steel tube analysis models. Zhong Shantong [13] and Han Linhai et al. [14] conducted several experiments on concrete-filled steel tubular columns and proposed the constitutive relationship of equivalent uniaxially-confined concrete. They performed the entire process analysis of the axial compression members through incremental method. However, the equivalent method was based on a large number of tests, and accurately describing the interaction between steel and concrete is difficult. Lakshmi et al. [15] proposed an analytical method for estimating the performance and bearing capacity of concrete members in inelastic state. Nonlinear equilibrium equations, considering geometry and material nonlinearity, were solved through an iterative process on the basis of generalized displacement control. The method assumed that the steel tube is in close contact with the concrete and did not consider the strain strengthening of the steel tube. Sakino et al. [16] analyzed the effects of different parameters, such as steel tube shape, steel tube tensile strength, steel tube diameter-thickness ratio, and concrete strength, on the mechanical properties of 114 concrete-filled steel tubular columns under axial compression. Design formulas to estimate the ultimate axial compressive load capacities were also provided. However, the interaction between the steel tube and concrete was not fully considered. Susantha et al. [17] presented a method for predicting the complete stress-strain curve of concrete subjected to triaxial compressive stresses caused by axial load plus lateral pressure due to the confinement action in circular, box and octagon shaped concrete-filled steel tubes. However, the lateral pressure exerted on the concrete is determined by available empirical formulas. Xiao et al. [18] proposed a confined concrete constitutive model, failure criterion, and flow criterion by using the octahedral stressstrain relationship through a series of experimental studies on transversely confined concrete axial columns. Choi et al. [19] improved Xiao's calculation procedures. Xiao et al. [20] presented a nonlinear analytical procedure by using the octahedral stress-strain relationship, the corresponding failure criterion, and flow rule. The simplified hardening model of steel tube, following the fundamental principles of elasto-plastic mechanics, was also introduced to predict the load-deformation curves of circular concrete-filled steel tube stub columns under axial compression. The interaction between the steel tube and core concrete was the focus, and a total of 16 interaction conditions between them were considered. Xiao's analysis method is simple and fully considers the development of the interaction between the steel tube and concrete under axial compression. A large number of experimental data also prove the rationality of the analytical method, but the concrete strength does not exceed $50 \mathrm{MPa}$ in this study. Thus, further study is needed to determine whether the method is suitable for high-strength concrete.

The emphasis of existing studies is mainly on the ordinary concrete of steel pipe. However, in comparison with ordinary concrete materials, RPC improves the internal pore structure and weak interface of concrete by improving the fineness and activity of the components and minimizing the pores and micro-cracks inside the material. The structure $[21,22]$ has obtained ultra-high strength and durability. The mechanical properties of RPC are different from those of ordinary concrete. Therefore, the existing analysis model for concrete-filled steel tube is unsuitable for RPC-filled steel tube structures.

Therefore, this study proposes a nonlinear analytical procedure to evaluate the mechanical properties of steel tube and RPC accurately at different compressing stages on the basis of classical elasto-plastic theory and material constitutive relations. This procedure is used to predict the load-deformation curves of RPC-filled steel tube stub columns under axial compression with incremental nonlinear analysis realized by coding a computer program using MATLAB.

The remainder of this study is organized as follows: Section 3 describes the experimental design and derivation of the characteristic hoop coefficient. Section 4 discusses the new analytical model and the applicability of the method by coding a computer program using MATLAB. Section 5 summarizes the conclusions 


\section{Methodology}

\subsection{General situation of the experiment}

Figure 1 shows a schematic view of the test setup. Tests are performed on a $5000 \mathrm{kN}$ capacity hydraulic testing machine. Axial forces are applied on the bearing plate and top endplate. Eight strain gauges are arranged on the symmetric axes of the mid-height section of the steel tube to measure the longitudinal and transverse strains. For all specimens, the axial deformations are collected by two linear voltage displacement transducers, as shown in Fig. 1.

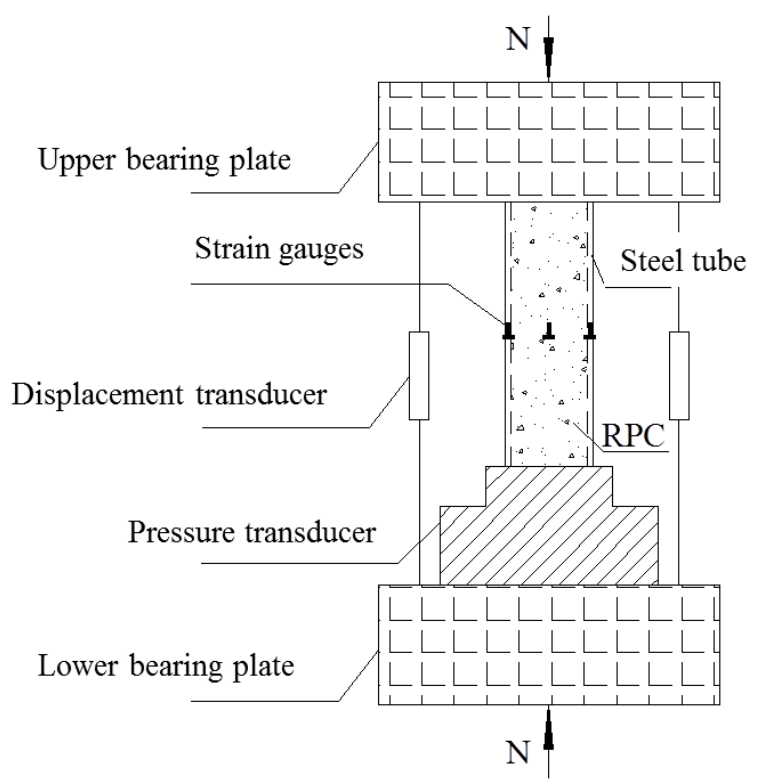

Fig. 1. Loading and measurement diagram

The interval load is applied. A load interval of less than one-tenth of the estimated load capacity is used before the steel is yielded, and less than one-twentieth of the estimated load capacity is utilized after the steel is yielded. Each load interval is maintained for approximately $3 \mathrm{~min}$. The test data are collected by using the Donghua DH3816 static strain measurement system.

\subsection{Analysis Method}

In the analyses of the RPC-filled steel tube column system, cross-sectional interactions between the steel tube and filledin RPC in the columns are categorized into two different conditions. One possible condition is that the gap is generated between the steel tube and RPC cylinder during loading. The typical Poisson's ratio of steel is higher than that of RPC; thus, the steel tube is transversely more expanded than RPC, thereby causing a gap between them. In this case, filled-in RPC and steel tube deformations are the same as under the uniaxial loading of each specimen. Both materials will be deformed without any interaction. Another possible condition is that the gap between the two materials is diminished when the filled-in RPC reaches its elastic limitation and starts plastic deformation, finally touching each other during the loading. The conditions with and without a gap are divided into four different material conditions in accordance with the elastic or plastic ranges of material statuses.

\subsubsection{Equilibrium Conditions}

In the analytical model of the equilibrium condition, the filled-in RPC column and steel tube are assumed to support the same amount of stress from the axial direction without stress from other directions. In addition, the surface of the RPC column and the inner surface of the steel tube completely contact each other when the gap between the concrete and steel tube is diminished. Figure 2 shows the cylindrical coordinate system of the RPC-filled steel tube columns in the equilibrium condition.
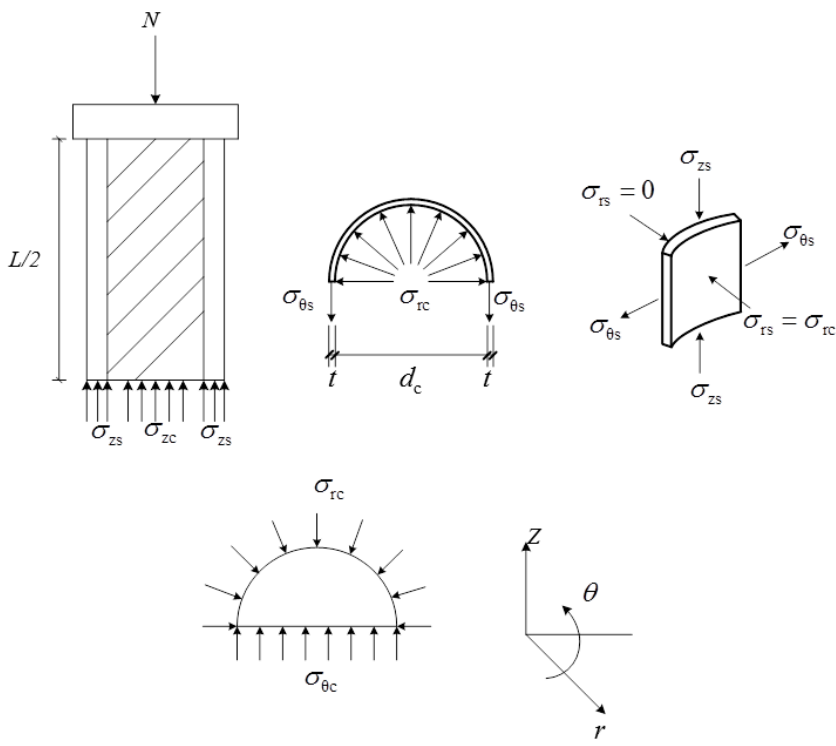

Fig. 2. Equilibrium relationship between filled-in RPC and steel tube

Considering this assumption, the entire applied load equals to the summation of loads on the filled-in RPC and steel tube. Moreover, the $\mathrm{r}$ - and $\theta$-direction stresses of the concrete column are identical. On the basis of the relationship between RPC and steel, the equilibrium equations can be represented as follows:

$$
\begin{aligned}
& N=A_{\mathrm{c}} \sigma_{\mathrm{zc}}+A_{\mathrm{s}} \sigma_{\mathrm{zs}} \\
& \sigma_{\theta \mathrm{c}}=\sigma_{\mathrm{rc}} \\
& \sigma_{\mathrm{rc}} d_{\mathrm{c}}=2 \sigma_{\theta \mathrm{s}} t
\end{aligned}
$$

Where $N$ is the applied axial load; $A_{\mathrm{c}}$ is the crosssection area of filled-in RPC; $A_{\mathrm{s}}$ is the cross-section area of steel tube; $d_{\mathrm{c}}$ is the inner diameter of steel tube; $t$ is the thickness of steel tube.

\subsubsection{Deformation Compatibility}

When a certain load applies to the RPC-filled steel tube columns, the axial deformations of the filled-in RPC and steel tube are presumed identical. Considering this assumption, the axial deformation compatibility of the RPCfilled steel tube columns can be represented as follows:

Z-direction:

$\varepsilon_{\mathrm{zc}}=\varepsilon_{\mathrm{zs}}$

Where $\varepsilon_{\mathrm{zc}}$ is the Z-directional strain of filled-in RPC; $\varepsilon_{\mathrm{zS}}$ is the Z-directional strain of steel tube.

$$
r-\theta \text { direction: }
$$

$\varepsilon_{\mathrm{rc}}=\varepsilon_{\theta \mathrm{c}}$ 
Where $\varepsilon_{\mathrm{rc}}$ is the $r$-directional strain of filled-in RPC; $\varepsilon_{\theta \mathrm{c}}$ is the $\theta$-directional strain of filled-in RPC.

$\theta$ direction:

$\varepsilon_{\theta \mathrm{c}}=\varepsilon_{\theta \mathrm{s}}$

Where $\varepsilon_{\theta \mathrm{c}}$ is the $\theta$-directional strain of filled-in RPC; $\varepsilon_{\theta \mathrm{c}}$ is the $\theta$-directional strain of steel tube.

\subsubsection{Constitutive Model}

The analysis of the constitutive model assumes that the filled-in RPC has a triaxial stress-strain relationship. The constitutive model of concrete under triaxial compression condition is complex, and only some models are available. In this study, Xiao's concrete constitutive model [18] is adopted for the constitutive model of RPC in RPC-filled steel tube columns under triaxial compression. To simplify the analytical analysis, the steel tube can be considered a biaxial stress-strain relationship because the steel tube in the RPC-filled steel tube columns is relatively thin. Considering these assumptions, the stress-strain relationship of the steel tube can be represented by the following 2D generalized Hook's law:

$$
\begin{aligned}
& \sigma_{1}=\frac{E_{\mathrm{s}}}{1-v_{\mathrm{s}}^{2}}\left(\varepsilon_{\mathrm{zs}}+v_{\mathrm{s}} \varepsilon_{\theta \mathrm{s}}\right) \\
& \sigma_{2}=\frac{E_{\mathrm{s}}}{1-v_{\mathrm{s}}^{2}}\left(\varepsilon_{\theta \mathrm{s}}+v_{\mathrm{s}} \varepsilon_{\mathrm{zs}}\right)
\end{aligned}
$$

Where $E_{\mathrm{s}}$ is the elastic modulus of steel tube; $\boldsymbol{v}_{\mathrm{s}}$ is the Poisson's ratio of steel tube.

\subsubsection{Analysis Process}

To analyze the interactions between filled-in RPC and steel tube in the RPC-filled steel tube column system, a total of 11 unknown variables - five RPC and steel stresses, five concrete and steel strain values, and one applied axial load should be defined to solve the problem of the entire system. Ten distinct equations can be obtained from Equations (1) to (5). If one numerical value is provided for one unknown variable, then the entire system can be numerically solvable because the number of unknown variables and corresponding equations is the same.

By inputting the first incremental axial strain value into the program, all stresses, other strains, and applied force values at the first loop will be calculated. Then, the next loop can be initialized by adding the incremental axial strain value to the previous axial strain value. This loop algorithm is continued until either steel tube or filled-in RPC reaches its yield strength. On the basis of these analytical assumptions and conditions, the detailed algorithms and solutions of all four different cases are described as follows.

The first case refers to the elastic range of RPC and steel tube. The generalized equilibrium conditions for this range can be expressed as follows:

$$
\begin{gathered}
\sigma_{\mathrm{rc}}=-\frac{2 t}{d_{\mathrm{c}}} \frac{E_{\mathrm{s}}}{1-v_{\mathrm{s}}^{2}}\left(\varepsilon_{\theta \mathrm{s}}+v_{\mathrm{s}} \varepsilon_{\mathrm{zs}}\right) \\
d \varepsilon_{\mathrm{rc}}=-\frac{3 K-2 G+R v_{\mathrm{s}}}{6 K+2 G+3 R} \varepsilon_{\mathrm{zc}}
\end{gathered}
$$

Where $R=\frac{2 t}{d_{\mathrm{c}}} \frac{E_{\mathrm{s}}}{1-v_{\mathrm{s}}^{2}}, K=\frac{E_{\mathrm{c}}}{3\left(1-2 v_{\mathrm{c}}\right)}$, and $G=\frac{E_{\mathrm{c}}}{2\left(1+v_{\mathrm{c}}\right)}$.

The second case refers to the elastic range of RPC and the plastic range of steel tube. In this case, the analysis of filled-in RPC is the same as in the first case. However, the plastic range of steel tube cannot handle stresses anymore because the steel tube only has plastic deformation after yielding. This condition follows the definition of the elastoperfect plastic stress-strain relationship. Thus, the axial stress increment can be represented as follows:

$$
\begin{aligned}
& d \varepsilon_{\mathrm{zs}}=d \varepsilon_{\mathrm{zs}}^{\mathrm{e}}+d \varepsilon_{\mathrm{zs}}^{\mathrm{p}} \\
& d \varepsilon_{\theta \mathrm{s}}=d \varepsilon_{\theta \mathrm{s}}^{\mathrm{e}}+d \varepsilon_{\theta \mathrm{s}}^{\mathrm{p}} \\
& \frac{d \varepsilon_{0 \mathrm{~s}}^{\mathrm{p}}}{d \varepsilon_{\mathrm{zs}}^{\mathrm{p}}}=\varphi_{\mathrm{p}} \\
& \frac{d \varepsilon_{\theta \mathrm{s}}^{\mathrm{e}}}{d \varepsilon_{\mathrm{zs}}^{\mathrm{e}}}=\varphi_{\mathrm{e}} \\
& d \sigma_{\mathrm{r}}=-\frac{2 t}{d_{\mathrm{c}}} \frac{E_{\mathrm{s}}}{1-v_{\mathrm{s}}^{2}}\left(d \varepsilon_{\theta \mathrm{s}}+v_{\mathrm{s}} d \varepsilon_{\mathrm{zs}}\right)=-\frac{2 t}{d_{\mathrm{c}}} \frac{E_{\mathrm{s}}}{1-v_{\mathrm{s}}^{2}}\left(1+\frac{v_{\mathrm{s}}}{\varphi_{\mathrm{e}}}\right) d \varepsilon_{0 \mathrm{~s}}^{\mathrm{e}}
\end{aligned}
$$

Therefore, $R^{\prime}=\frac{2 t}{d_{\mathrm{c}}} \frac{E_{\mathrm{s}}}{1-v_{\mathrm{s}}^{2}}\left(1+\frac{v_{\mathrm{s}}}{\varphi_{\mathrm{e}}}\right)$.

Then, the following equations are obtained:

$$
d \sigma_{\mathrm{r}}=-R^{\prime} d \varepsilon_{\theta \mathrm{s}}^{\mathrm{e}}
$$

$d \varepsilon_{\theta \mathrm{s}}^{\mathrm{e}}=-\frac{3 K-2 G+\varphi_{\mathrm{p}}(6 K+2 G)}{3 R^{\prime}+(6 K+2 G)\left(1-\frac{\varphi_{\mathrm{p}}}{\varphi_{\mathrm{e}}}\right)} d \varepsilon_{\mathrm{zc}}$

$d \varepsilon_{\mathrm{rc}}=\varphi_{\mathrm{p}} d \varepsilon_{\mathrm{zc}}+\left(1-\frac{\varphi_{\mathrm{p}}}{\varphi_{\mathrm{e}}}\right) d \varepsilon_{\theta \mathrm{s}}^{\mathrm{e}}$

The third case refers to the plastic range of RPC and the elastic range of steel. In this case, the analysis of steel is the same as in the first case. However, the plastic range of RPC should be calculated by separating elastic deformation from plastic deformation. Thus, the RPC strain can be divided into elastic and plastic strains as follows:

$d \varepsilon_{\mathrm{zc}}=d \varepsilon_{\mathrm{zc}}^{\mathrm{e}}+d \varepsilon_{\mathrm{zc}}^{\mathrm{p}}$
$d \varepsilon_{\mathrm{rc}}=d \varepsilon_{\mathrm{rc}}^{\mathrm{e}}+d \varepsilon_{\mathrm{rc}}^{\mathrm{p}}$

The fourth case refers to the plastic range of RPC and steel. The analysis of this case is easily obtained by combining the plastic analytical parts of the second and third cases.

\section{Result Analysis and Discussion}

On the basis of the test in Section 3.1, the failure modes of the specimens are obtained, as shown in Fig. 3. The axial pressure failure modes of the specimens are ductile failure modes, and evident deformations are observed. 


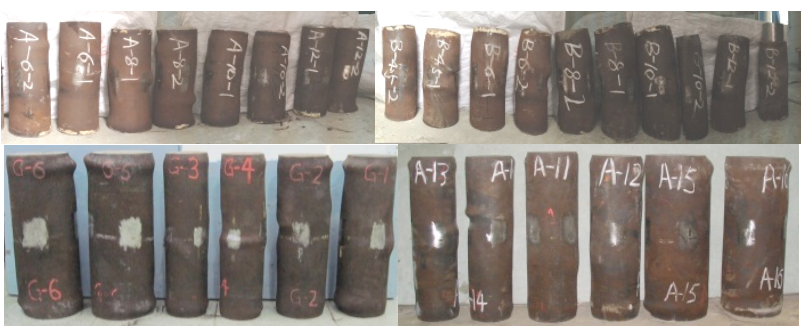

Fig. 3. Failure modes of specimens

The typical load-deformation curves of the RPC-filled steel tube stub columns under axial compression are derived by summarizing the existing experimental results, as shown in Fig. 4. The basic shape of such curves is related to the hoop coefficient $\xi$.

When $\xi<\xi_{0}$, the curves fall after reaching a certain peak point, as shown by curve a in Fig. 4 .

When $\xi=\xi_{0}$, the curves are flat, as shown by curve b in Fig. 4.

When $\xi>\xi_{0}$, the curves have a reinforcement segment, as shown by curve c in Fig. 4 .

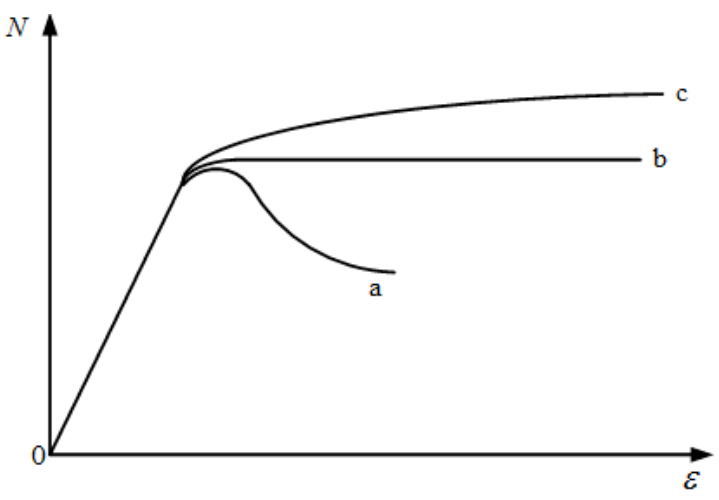

Fig. 4. Typical load-deformation curves

Figure 5 shows the longitudinal stress $\frac{\sigma_{\mathrm{c}}}{f_{\mathrm{c}}}$ and confining stress $\frac{\sigma_{\mathrm{r}}}{f_{\mathrm{c}}}$ relationship of the RPC.

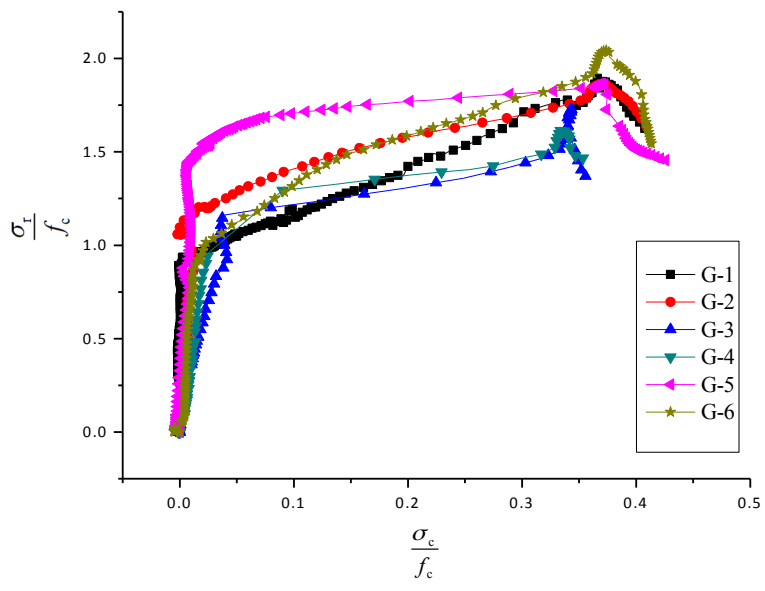

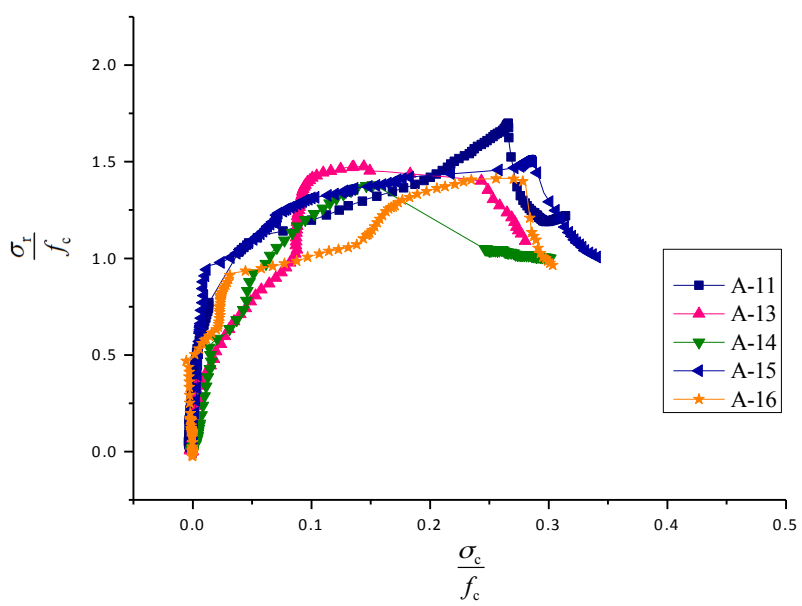

Fig. 5. $\frac{\sigma_{\mathrm{c}}}{f_{\mathrm{c}}}-\frac{\sigma_{\mathrm{r}}}{f_{\mathrm{c}}}$ curves for specimens

The functional form of $\frac{\sigma_{\mathrm{c}}}{f_{\mathrm{c}}}-\frac{\sigma_{\mathrm{r}}}{f_{\mathrm{c}}}$ relationship in Fig.5. can be expressed as follows:

$$
\frac{\sigma_{\mathrm{c}}}{f_{\mathrm{c}}}=-33.805\left(\frac{\sigma_{\mathrm{r}}}{f_{\mathrm{c}}}\right)^{2}+12.608\left(\frac{\sigma_{\mathrm{r}}}{f_{\mathrm{c}}}\right)
$$

The functional form of the longitudinal stress of steel tube based on unified strength theory is as follows:

$$
\begin{aligned}
\sigma_{\mathrm{zs}} & =f_{\mathrm{y}}-\frac{1}{1+b}\left(\sigma_{\theta \mathrm{s}}-b \sigma_{\mathrm{r}}\right) \\
& =f_{\mathrm{y}}-\frac{1}{1+b}\left(\sigma_{\mathrm{r}} \frac{2 A_{\mathrm{c}}}{A_{\mathrm{s}}}-b \sigma_{\mathrm{r}}\right) \\
& =f_{\mathrm{y}}-\frac{\sigma_{\mathrm{r}}}{1+b}\left(\frac{2 A_{\mathrm{c}}}{A_{\mathrm{s}}}-b\right)
\end{aligned}
$$

Where $\sigma_{\mathrm{zs}}$ is the z-directional stress of the steel tube, $\sigma_{\theta \mathrm{s}}$ denotes the $\theta$-directional stress of the steel tube, $f_{\mathrm{y}}$ indicates the yield strength of the steel tube, and $b$ is a coefficient ranging between 0 and 1 .

Considering the relationship between RPC and steel, the equilibrium equation can be represented as follows:

$N=A_{\mathrm{c}} \sigma_{\mathrm{c}}+A_{\mathrm{s}} \sigma_{\mathrm{zs}}$

If Equations (16) and (17) are plugged into Equation (18), the equilibrium equation can be expressed as follows:

$$
\begin{aligned}
N & =A_{\mathrm{c}} \sigma_{\mathrm{c}}+A_{\mathrm{s}} \sigma_{\mathrm{zs}} \\
& =A_{\mathrm{c}} f_{\mathrm{c}}\left[-33.805\left(\frac{\sigma_{\mathrm{r}}}{f_{\mathrm{c}}}\right)^{2}+12.608\left(\frac{\sigma_{\mathrm{r}}}{f_{\mathrm{c}}}\right)\right]+A_{\mathrm{s}}\left[f_{\mathrm{y}}-\frac{\sigma_{\mathrm{r}}}{1+b}\left(\frac{2 A_{\mathrm{c}}}{A_{\mathrm{s}}}-b\right)\right]
\end{aligned}
$$

In Equation (19), $N$ is quadratic related with $\sigma_{\mathrm{r}}$. Let $\frac{d N}{d \sigma_{\mathrm{r}}}=0$. Then,

$\sigma_{\mathrm{r}}=f_{\mathrm{c}}\left(0.186-\frac{2-\frac{A_{\mathrm{s}}}{A_{\mathrm{c}}} b}{67.61(1+b)}\right)$ 
When the RPC-filled steel tube columns reach the ultimate bearing capacity, $\sigma_{\theta \mathrm{s}}$ satisfies the following equation:

$\sigma_{\theta \mathrm{s}}=\frac{2 A_{\mathrm{c}} f_{\mathrm{c}}}{A_{\mathrm{s}}}\left(0.186-\frac{2-\frac{A_{\mathrm{s}}}{A_{\mathrm{c}}}}{67.61(1+b)}\right) \leq f_{\mathrm{y}}$

Given that $\frac{1}{\xi}=\frac{A_{\mathrm{c}} f_{\mathrm{c}}}{A_{\mathrm{s}} f_{\mathrm{y}}}$, Equation (21) can be expressed as follows:

$$
\xi \geq 1.372-\frac{2-\frac{A_{\mathrm{s}}}{A_{\mathrm{c}}} b}{33.805(1+b)}
$$

$$
\text { Consider that } \xi_{0}=1.372-\frac{2-\frac{A_{\mathrm{s}}}{A_{\mathrm{c}}} b}{33.805(1+b)} \text {. }
$$

$\xi_{0}$ is the critical value for assessing whether the steel tube yields when the RPC-filled steel tube columns reach the ultimate bearing capacity. $\xi_{0}$ is also the basis for judging the development trend of the axial stress-strain curve after peak stress. Columns with $\xi<\xi_{0}$ have good ductility, but the material utilization rate of the steel tube is not high. Columns with $\xi>\xi_{0}$ have weak ductility and residual deformation capacity. Moreover, columns with $\xi_{0}$ can reach good ductility and high material utilization rate. The characteristic hoop coefficient determined by the test analysis in this study is approximately 1.3.

Figure 6 shows the experimental result and analytical stress-strain relationship calculated by analytical solution. Analytical results are in good agreement with the experimental results until the starting position of strain hardening or local plastic buckling.

For specimens with medium diameter-to-thickness ratio, analytical results are well matched to experimental results, as shown in Fig. 6. Specimens with high and low diameterto-thickness ratio show a slightly different trend with experimental results, but the yield strength of specimens are closely estimated. These results are expected because some factors, such as strain hardening and buckling effects, are ignored by the assumption in this study to match with experimental results.

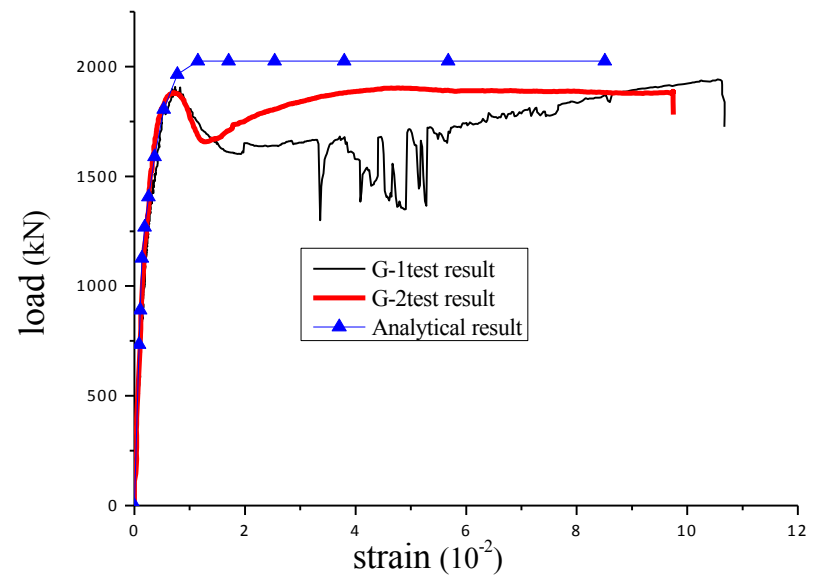

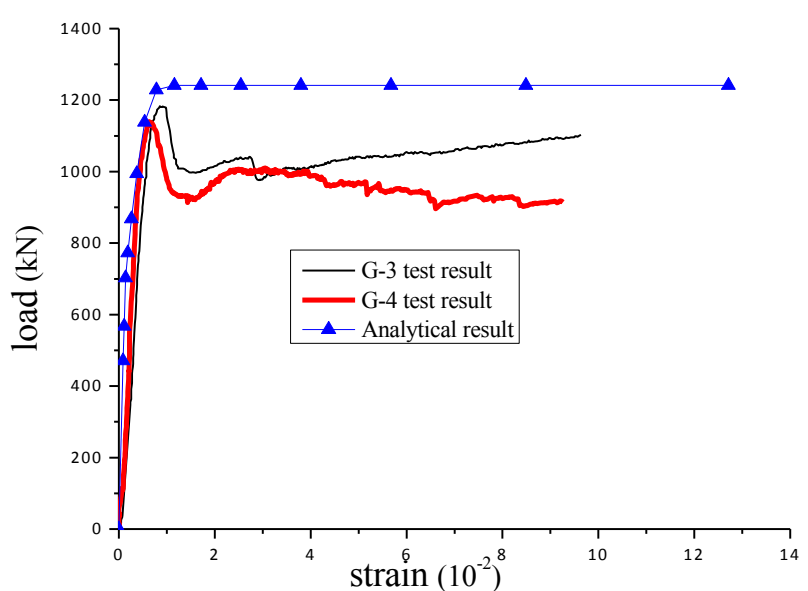
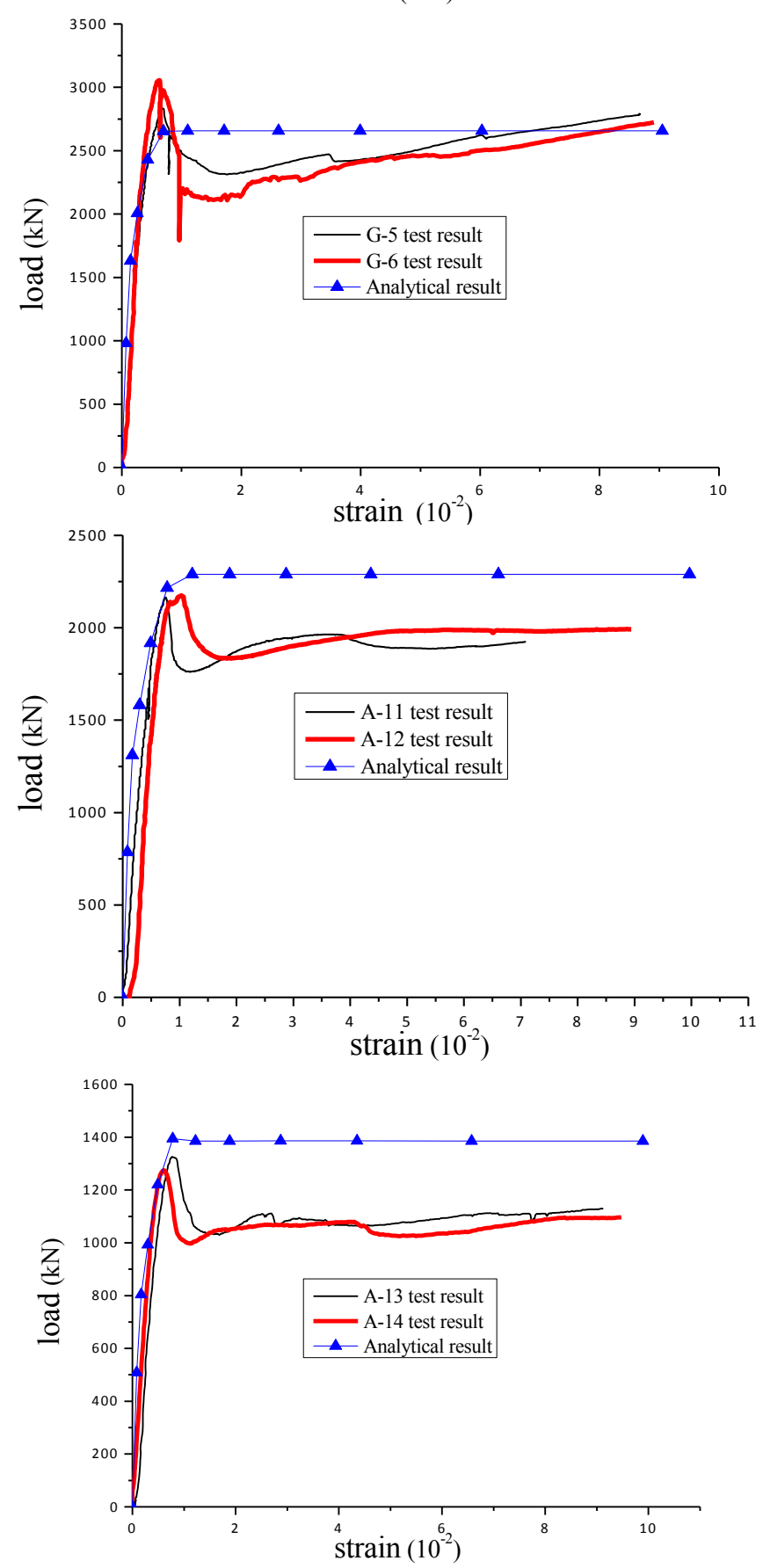


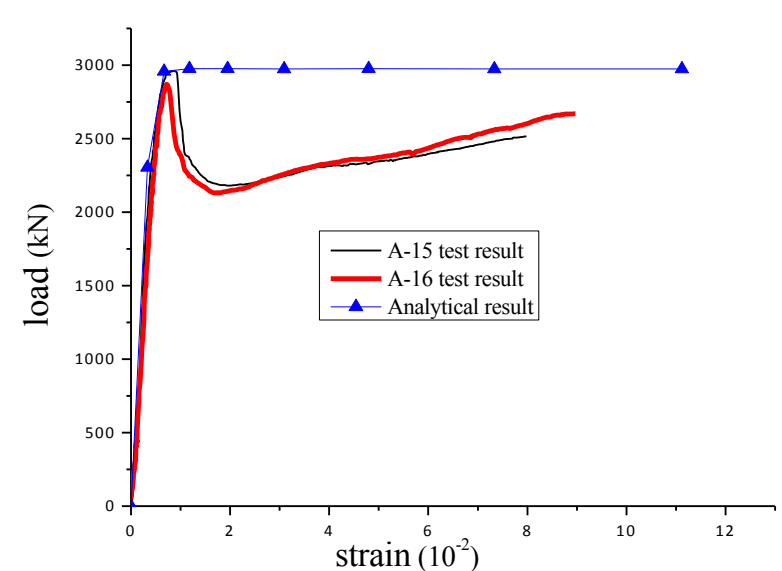

(a) Small hoop coefficient
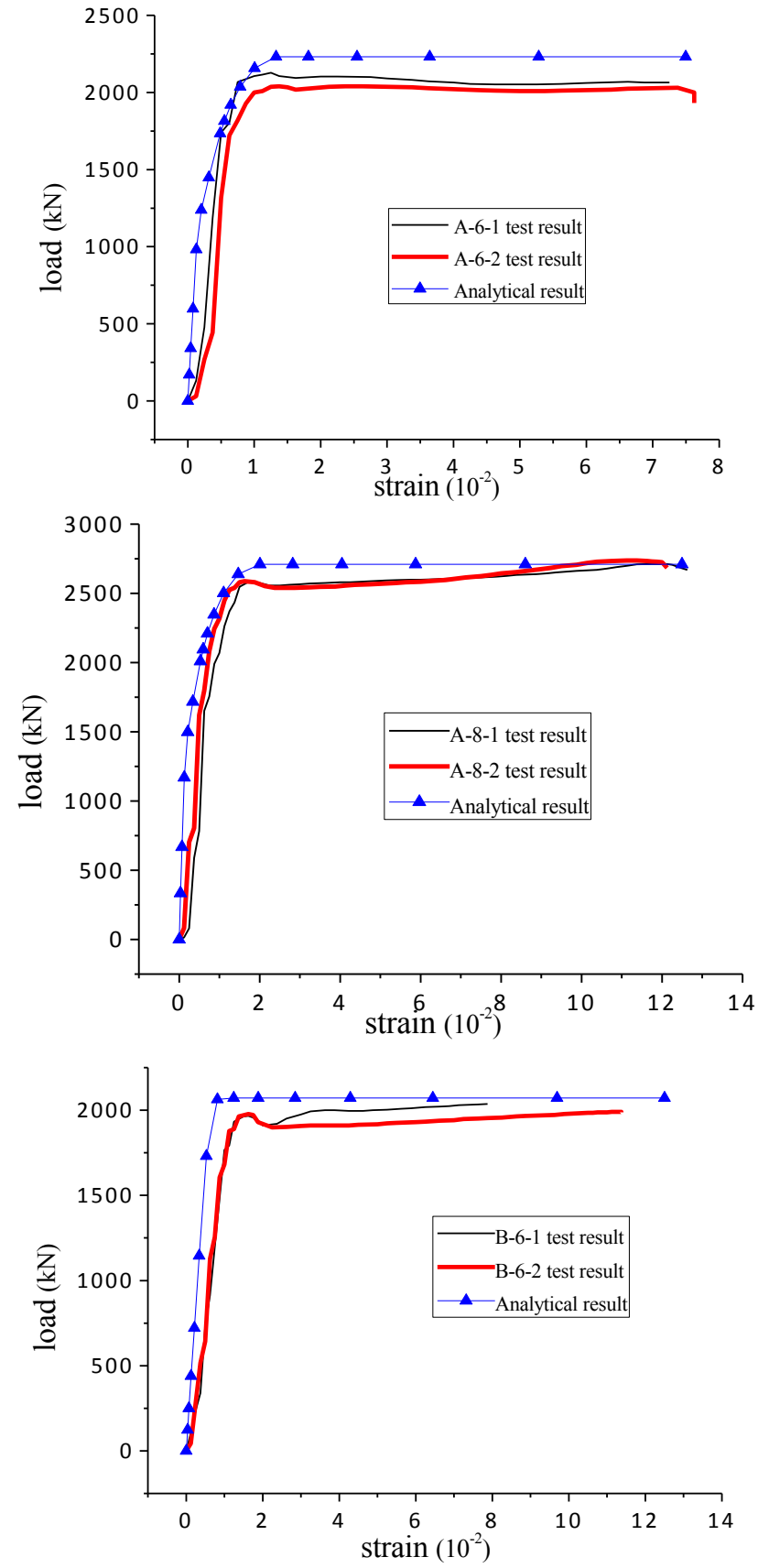

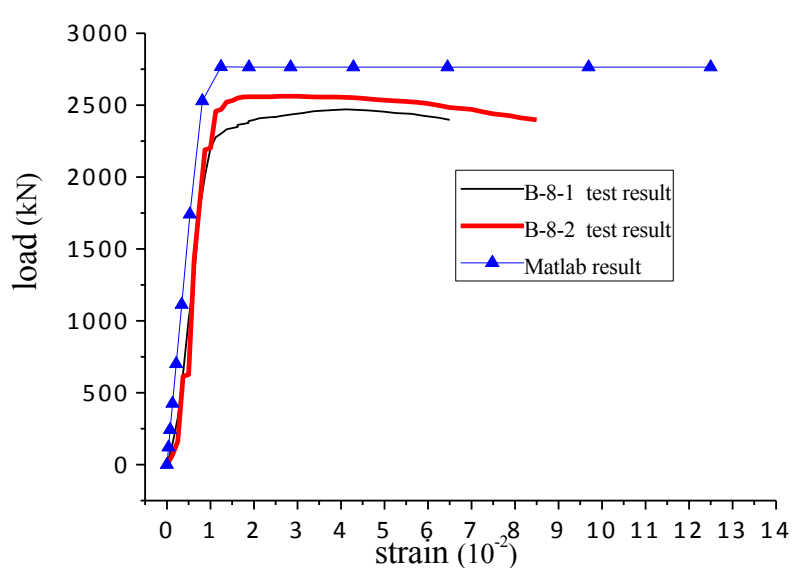

(b) Medium hoop coefficient
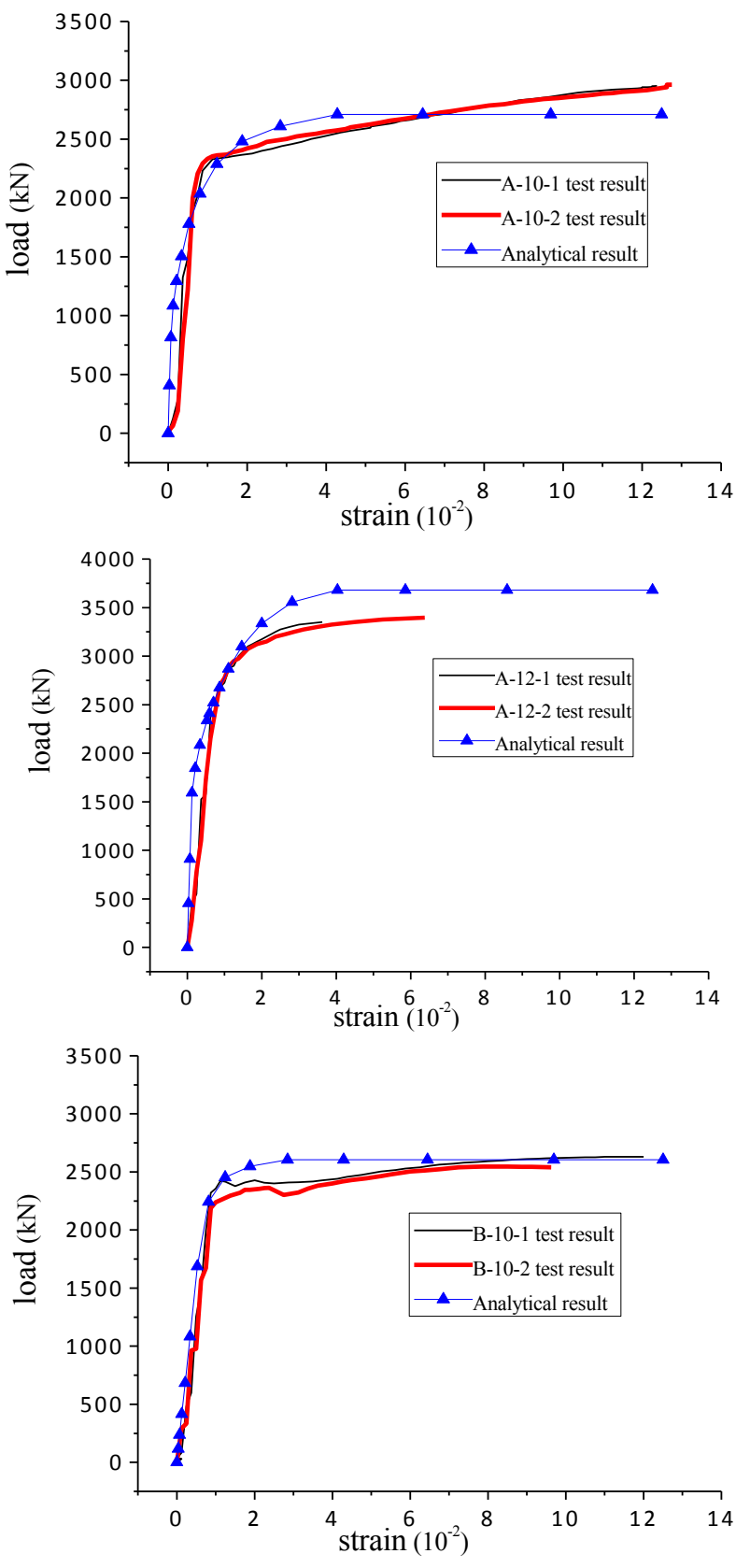


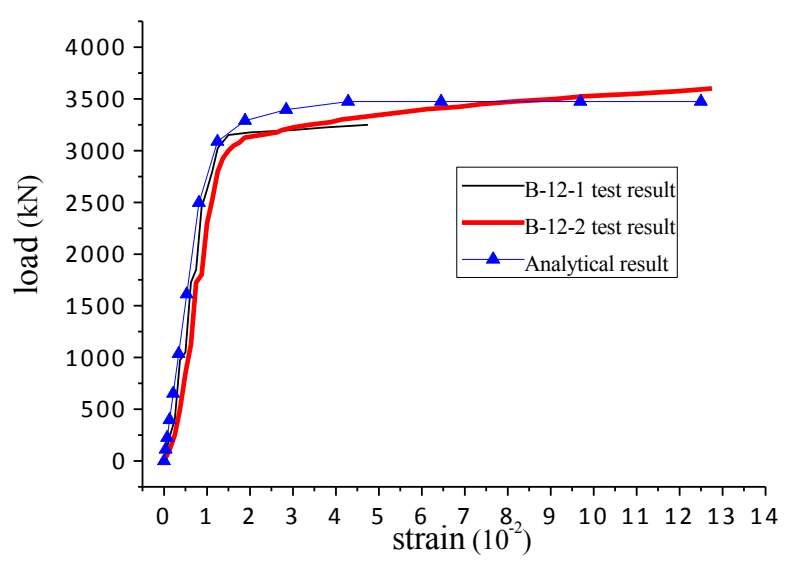

(c) Large hoop coefficient

Fig. 6. Comparison of the analytical solution and test result

\section{Conclusion}

To evaluate the mechanical properties of RPC-filled steel tube stub columns under axial compression, a nonlinear analytical procedure was presented using the octahedral stress-strain relationship, the corresponding failure criterion, and flow rule. The simplified hardening model of steel tube was also introduced. Comparison analysis was performed to verify the accuracy and efficiency of the analytical procedure. The following conclusions were drawn:

(1) $\xi_{0}$ is the critical value for determining whether the steel tube yields when the RPC-filled steel tube columns reach the ultimate bearing capacity. $\xi_{0}$ is also the basis for assessing the development trend of the axial stress-strain curve after peak stress. Columns with $\xi<\xi_{0}$ have good ductility, but the material utilization rate of the steel tube is not high. Columns with $\xi>\xi_{0}$ have weak ductility and residual deformation capacity. Moreover, columns with $\xi_{0}$ can reach good ductility and high material utilization rate.
The characteristic hoop coefficient determined by the test analysis in this study is approximately 1.3 .

(2) The analytical results are in good agreement with the experimental results until the starting position of strain hardening or local plastic buckling. For specimens with medium diameter-to-thickness ratio, analytical results are well matched to experimental results. Specimens with high and low diameter-to-thickness ratio show a slightly different trend with experimental results, but the yield strength of specimens is closely estimated. These results are expected because some factors, such as strain hardening and buckling effects, are ignored by the assumption in this study to match with experimental results.

Thus, the proposed analytical procedure for RPC-filled steel tube columns under axial compression has a clear concept, and the unknown parameters can be easily confirmed. In addition, the procedure can predict the loaddeformation curves of the RPC-filled steel tube columns under axial compression. Further analysis of the working performance of the RPC-filled steel tube structure in the complex mechanical and plastic state is possible. However, given that the procedure requires some material parameters and the RPC performance considerably varies with different mixtures of composition material, parameters in the actual condition can deviate. Therefore, future studies should consider additional parameters that influence the performance of the material to expand the application of the procedure and investigate the performance of the RPC-filled steel tube structure further in a complex stress state.

\section{Acknowledgments}

This work was supported by the National Natural Science Foundation of China (Project No. 51708209) and the program of the Hunan Provincial Education Department (Project No. 16C0725).

This is an Open Access article distributed under the terms of the Creative Commons Attribution License

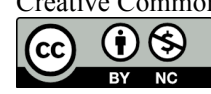

\section{References}

1. Hao W, Xu X, Niu Z. "Experimental study on the mechanical behavior of RPC filled square steel tube columns subjected to eccentric compression”. Frattura ed Integrità Strutturale, 12(46), 2018, pp.391-399.

2. ZOU Hui-hui, CHEN Wan-xiang, JIANG Meng. "Research status of the mechanical properties of RPC filled steel tube column and limit analysis". Concrete, (2), 2016, pp.29-33.

3. Chen W, Luo L, Guo Z, et al. "Strain rate effects on dynamic strength of high temperature-damaged RPC-FST". Journal of Constructional Steel Research, 147, 2018, pp.324-339.

4. Wang Y B, Liew J Y R, Lee S C, et al. "Experimental Study of Ultra-High-Strength Concrete under Triaxial Compression". Aci Materials Journal, 113(1), 2016, pp.105-112.

5. Noori A, Shekarchi M, Moradian M, et al. "Behavior of Steel FiberReinforced Cementitious Mortar and High-Performance Concrete in Triaxial Loading”. Aci Materials Journal, 112(1), 2015, pp.95104.

6. Luo H, Wang W, Shen L, et al. "Stress-Strain Model for Reactive Powder Concrete Confined by Steel Tube". Journal of Engineering Science \& Technology Review, 10(2), 2017, pp.122-131.

7. Hua L, Wen-Yu J I, Yan Z G, et al. "Research on Influence of Loading Methods on Compressive Behavior of Reactive Powder Concrete Filled Steel Tube Stub Columns under Axial Loads". Journal of the China Railway Society, 36(9), 2014, pp.105-110.
8. Min Y U, Zha X, Jianqiao Y E, et al. "A unified formulation for circle and polygon concrete-filled steel tube columns under axial compression". Engineering Structures, 49(2), 2013, pp.1-10.

9. Wang J, Chen W, Guo Z, et al. "Dynamic Responses of RPC-Filled Steel Tubular Columns Post Fire Under Blast Loading”. Open Civil Engineering Journal, 10(1), 2016, pp.236-245.

10. Chen W, Guo Z, Zhang T, et al. "Near-field blast test on Reactive Powder Concrete-Filled Steel Tubular columns after exposure to fire". International Journal of Protective Structures, 7(2), 2016, pp.193-212.

11. Zou Hui-hui, Chen Wan-xiang, GUO Zhi-kun, et al. "Tests for blast-resistant capacities of RPC filled steel tubular columns after exposure to fire". Journal of Vibration and Shock, 35(13), 2016, pp.1-7.

12. Chen W, Luo L, Guo Z, et al. "Strain rate effects on dynamic strength of high temperature-damaged RPC-FST". Journal of Constructional Steel Research, 147, 2018, pp.324-339.

13. Zhong Shantong. "Concrete filled steel tubular structures".Harbin: Science and Technology Press,1994, pp. 48-67.

14. Han Linhai, Zhong Shantong. "Mechanics of concrete filled steel tubular columns". Dalian: Dalian University of Science and Technology Press, 1996, pp. 101-141.

15. Lakshmi B,Shanmugam N E. Nonlinear analysis of infilled steelconcrete composite columns. Journal of Structural Engineering, 128(7), 2002, pp.922-933. 
16. Sakino K, Nakahara H, Morino S, Nishiyama I.Behavior of centrally loaded concrete-filled steel-tube short columns. Journal of Structural Engineering, 130( 2), 2004, pp.180-188.

17. Susantha K A S, Ge H B, Usami T. Uniaxial stress strain relationship of concrete confined by various shaped steel tubes. Engineering Structures, 23(10), 2001, pp.1331-1347.

18. Xiao Y, Huang X. Analytical study of circular concrete-filled steel tube stub columns under axial compression. Journal of Building Structures, 32(12), 2011, pp.195-201.

19. Choi K K, Xiao Y. Analytical studies of concrete-filled circular steel tubes under axial compression. Journal of Structural Engineering, ASCE, 136( 5), 2010, pp.565-573.
20. Xiao yan, Huang xu. Analytical study of circular concrete-filled steel tube stub columns under axial compression. Journal of Building Structures, 32(12), 2011, pp.195-201.

21. Gökçe H S, Yalçınkaya Ç, Tuyan M. Optimization of reactive powder concrete by means of barite aggregate for both neutrons and gamma rays. Construction and Building Materials, 189, 2018 , pp.470-477.

22. Hou X, Cao S, Rong Q, et al. Effects of steel fiber and strain rate on the dynamic compressive stress-strain relationship in reactive powder concrete. Construction and Building Materials, 170, 2018, pp.570-581. 